\title{
To engage or not to engage - a modern representative's dilemma
}

Send your comments to the

Editor-in-Chief,

British Dental Journal

64 Wimpole Street,

London

W1G 8YS

Email bdj@bda.org

\author{
Peter Ward \\ Chief Executive, BDA
}

The landscape of the modern political environment is complex and challenging. When interacting with government, representative organisations are often called upon to co-operate in the consideration of issues and to inform policy-making.

Winning poll position as the principal representation organisation for any group is a cherished goal. And having won that position, such bodies guard it carefully and are constantly on the look-out for the pretenders who may wish to wrest it from them or whom the government may prefer as a more favourable correspondent.

As a consequence of the preferred status, most representative organisations take their responsibilities and regard the invitations to participate very seriously. But the invitation itself and the reaction to it is often fraught with difficulty and potential conflicts. If such an invitation is declined, the organisation is likely to be criticised as having not taken a valuable opportunity to be influential in policy formation. If the invitation is accepted the organisation runs the risk that when the policy is created and finalised it will be given an unreal and unreasonable level of responsibility for that policy. It may be that prudence dictates that presence and participation is best but the risk is that this will be perceived as endorsement or, even worse, co-culpability.

\section{AN IMPLIED IMPRIMATUR}

Governments have a difficult job to do, marrying political preferences with financial restrictions, with implementation challenges, with stakeholder buy-in and with public acceptance. Different components of this complex picture will have higher priority than others at different times. In a technically sophisticated world the servants of government are rightfully dependent upon experts to advise them on the content of policy to ensure that they are fully informed and do not make mistakes. But having validated the facts and elicited the art of the possible, they then have to shift into a mode that seeks to implement the political will of their masters. And so within the same exercise there are parts that are truly consultative and there are others that are just about ensuring the technical accuracy. But after the event there is vulnerability, either to genuine misunderstanding, or more worryingly to a manipulative attempt to imply a level of co-ownership that never existed and was never intended.

Indeed, the more Machiavellian thinkers would sometimes assert that this outcome was neither misunderstanding nor an afterthought. Some worry that in particular cases the involve- ment of the representative organisation is predetermined and planned as part of the mission to gain an implied imprimatur. They would say that the group's involvement was significantly no more than a show or a staged demonstration of pseudo-consultation to be used after the event to validate the pre-ordained will of the policy makers.

Whilst, by and large, the truth is probably seldom clear cut it is likely that a combination of opportunism and desperation leads to occasional manipulation in these cases. But the result is very damaging; it can lead to distrust and anxiety and can compromise relationships to the point where the recognised need for the input of experts is impeded and so decisions are not as good as they might be. The natural 'once bitten twice shy' instinct means that where an expert's (or expert organisation's) participation has been once misrepresented as ownership, there may be reluctance to participate again. As stated above there are, of course, legions of other experts or expert organisations who would like to take their place at the table. And so as the most obvious relationship is damaged beyond repair, the policy-former may be tempted to lower its sights and accept the input of second, third and fourth best. This erosion of confidence and generation of mistrust is not in the public interest as it impedes proper dialogue and compromises the quality of decisions.

So from all of this, my conclusion is that it is the duty of expert representative organisations to engage and inform public policy-makers but that in their turn they have a responsibility to respect the position of those organisations. They must not overstate the significance of their participation. They must not imply ownership where it does not exist. And they must accept that individual engagements are separate and discrete - in other words where the two bodies have had to agree to disagree on a matter, the mature policy-former should not use that as a stick to beat the expert organisation with in future discussions.

Ultimately this is a question of restoring mutual respect. It means saying 'I understand that you have a difficult job to do - but you must understand that so do I. I will try to provide you with as much advice and support as I can to allow you to improve the quality of your decision meeting. But you must understand that in doing so I am not endorsing the decision that is ultimately, rightfully and solely yours. You must understand that when I think you are wrong I have a duty to say so. It isn't personal and nor is it compromised by my earlier involvement'. And you never know - occasionally I might even be right!

DOI: 10.1038/sj.bdj.2009.1084 